PAEDIATRIC LUNG DISEASE

\title{
Chlamydophila pneumoniae and Mycoplasma pneumoniae in respiratory specimens of children with chronic lung diseases
}

\author{
N Teig, A Anders, C Schmidt, C Rieger, S Gatermann
}

Thorax 2005;60:962-966. doi: 10.1136/thx.2005.041004

\begin{abstract}
See end of article for authors' affiliations

Correspondence to:

Dr N Teig, Klinik für

Kinder- und

Jugendmedizin der Ruhr-

Universität, St-Josef-

Hospital, Alexandrinenstr

5, D-44791 Bochum,

Germany; norbert.teig@

rub.de
\end{abstract}

Received 31 January 2005

Accepted 7 August 2005

Published Online First

2 September 2005

\begin{abstract}
Background: Persistent infection with Mycoplasma pneumoniae and Chlamydophila pneumoniae has been implicated in the progression or induction of asthma and chronic obstructive pulmonary disease. Evidence for this hypothesis has been obtained in adults either by serological methods or by direct pathogen detection using invasive procedures.

Methods: We investigated nasal brush specimens and induced sputum from 38 children with stable chronic lung disease (asthma, $n=26$; chronic bronchitis $n=12$ ) and from 42 healthy controls for the presence of $M$ pneumoniae or $C$ pneumoniae DNA by polymerase chain reaction (PCR) using nested primers.

Results: None of the controls but $23.6 \%$ and $10.5 \%$ of the children with lung disease had positive PCR for $C$ pneumoniae $(p=0.001)$ and $M$ pneumoniae $(p=0.044)$ respectively. Significantly more children with non-atopic asthma than with atopic asthma were positive for $C$ pneumoniae or M pneumoniae $(4 / 8 \mathrm{v}$ $1 / 18 ; p=0.018)$. There were no unwanted side effects from sputum induction. No correlation was found between detection of Chlamydophila and severity of lung disease. Colonisation with both organisms had occurred before adulthood in a significant proportion of children with stable chronic lung diseases.

Conclusion: Combining nasal brush specimens with induced sputum may be a useful non-invasive method for studying the role of $C$ pneumoniae and $M$ pneumoniae infection in children with different chronic lung diseases.
\end{abstract}

infection with CP occurs at a low replicative state. ${ }^{28}$ Culture techniques for MP or CP are insensitive even in cases of acute infection when compared with DNA based techniques ${ }^{29}{ }^{30}$ and are not therefore suitable for the diagnosis of persistent infection.

There are few studies using PCR techniques in asthmatics without acute exacerbations. Only one study done in adults with chronic asthma included an appropriate control group. ${ }^{31}$ In this study MP and, to a lesser degree, CP were detected in a significant proportion of patients but most patients were only positive in bronchial biopsy specimens, precluding the use of this method on a large scale basis. Two other uncontrolled studies performed in children with asthma reported positive results for CP DNA in $25 \%$ of nasal aspirates ${ }^{24}$ and bronchoalveolar lavage specimens. ${ }^{32}$

As early (but not late) antibiotic treatment of experimental $\mathrm{CP}$ infection protects animals from developing atheromatous plaques, ${ }^{33}$ information on the age at which chronic infection can be detected may be important for intervention studies. We therefore investigated the role of both organisms in school children with stable chronic lung diseases (asthma, chronic purulent bronchitis) and children without lung disease by PCR analysis of induced sputum and nasal brush specimens.

\section{METHODS \\ Patients}

Children aged 6-16 years with either asthma or chronic purulent bronchitis and controls without lung disease were enrolled prospectively in several outpatient clinics of our

Abbreviations: $\mathrm{CP}$, Chlamydophila pneumoniae; $\mathrm{FEV}_{1}$, forced expiratory volume in 1 second; MP, Mycoplasma pneumoniae; PCR, polymerase chain reaction 
hospital. They were classified as having asthma if they had had a physician's diagnosis of asthma and recurrent (at least two) episodes of wheezing during the previous 12 months. Chronic purulent bronchitis was defined as daily sputum production over more than 2 years and at least two positive sputum cultures for conventional bacteria within this period. Atopy was defined as at least one positive specific IgE (CAP or RAST class $>1$ ) or skin prick test (weal $>2 \mathrm{~mm}$ ) to seven common inhalant allergens during the preceding 3 years. Control children were considered suitable for inclusion in the study if they had no history of recurrent wheezing or chronic sputum production, and normal lung function and auscultation of the lungs on the day of the study. They suffered from a range of non-pulmonary conditions including insulin dependent diabetes mellitus, mental and/or behavioural problems, epilepsy, resolving gastroenteritis, burn wounds in the stage of scarring, and benign haematological conditions.

Controls and patients were excluded from the study if they had received one or more courses of antibiotics during the previous 3 months with activity against Chlamydophila or Mycoplasma (such as macrolides, tetracyclines or quinolones) or had evidence of an acute exarcerbation of their underlying lung disease during this time period. Patients with immunodeficiencies were excluded.

The study was performed for patients and controls from June to October 1999 and from April to September 2000. All children underwent lung function testing using forced expiratory flow-volume curves (Bodyscreen, Jaeger/Viasys, Germany) and results were expressed as percentages of predicted for age and length of the children.

The study was approved by the institutional review board of the medical faculty of Ruhr-University Bochum and all study procedures were performed after informed consent of the parents and the child had been obtained.

\section{Sputum induction and processing}

Sputum was induced using a nebuliser (Pari Boy, Starnberg, Germany) with increasing concentrations of saline (starting at $0.9 \%$ and increasing every 5 minutes up to a concentration of $5.8 \%$ ). Every 5 minutes a flow-volume curve was obtained. A fall in forced expiratory volume in 1 second $\left(\mathrm{FEV}_{1}\right)$ of more than $20 \%$ from baseline was considered to be a criterion to stop the induction procedure. Children were asked to perform coughs every 2-3 minutes and the sputum was collected in a petri dish. Macroscopically visible sputum was separated from saliva and processed according to published protocols. ${ }^{34}$ Part of the sputum sample was weighed and mixed for 30 seconds with four times the volume of $0.1 \%$ dithiotreitol (DTT) by gentle aspiration in and out of a Pasteur pipette and rocked for 15 minutes on a bench rocker. The sample was diluted with an equal volume of Hank's balanced salt solution (HBSS) and the resulting suspension was filtered through a $48 \mu \mathrm{m}$ gauze. The filtered suspension was centrifuged at $300 \mathrm{~g}$ for 10 minutes. The cell pellet was resuspended in HBSS and squamous cell contamination was determined after staining. Patients with macroscopically insufficient sputum or with differential counts containing more than $50 \%$ squamous cells were excluded from further analysis.

The rest of the unprocessed sputum was frozen at $-70^{\circ} \mathrm{C}$ for microbiological analysis.

\section{Nasal specimens}

Nasal specimens were obtained by brush biopsy using a $2 \mathrm{~mm}$ cytology brush (BC-15 AE, Olympus) which was moistened with sterile normal saline before being introduced into the nose. The lateral inferior turbinate was brushed three times at a length of $4-5 \mathrm{~cm}$. The material was suspended in normal saline and stored at $-70^{\circ} \mathrm{C}$ until analysis. If no macroscopically visible material was recovered, the procedure was repeated. Previous studies in our laboratory have shown that this method yields sufficient cells $\left(10^{5}-10^{6}\right.$ viable cells/ $\mathrm{ml}$ ) in $>96 \%$ of specimens obtained from healthy school children.

\section{Detection of Mycoplasma pneumoniae and Chlamydophila pneumoniae DNA by nested PCR}

The laboratory investigators were blind to the patients' data.

\section{Mycoplasma pneumoniae}

A total of $500 \mu \mathrm{l}$ nasopharyngeal brush specimen or induced sputum submitted from the Children's Hospital was pretreated with $0.5 \%$ acetyl cysteine and centrifuged for 30 minutes at $15000 \mathrm{~g}$ at $4{ }^{\circ} \mathrm{C}$. DNA was extracted from the pellet with a QIAamp DNA Mini Kit (Qiagen, Hilden, Germany) according to the manufacturer's protocol. The MP specific primer pair MP-1 5'-GAA GCT TAT GGT ACA GGT TGG $3^{\prime}$ and MP-2 5'-ATT ACC ATC CTT GTT GTA ACG3' (MWG-Biotech, Ebersburg, Germany) described by Bernet, ${ }^{35}$ coding for a fragment of the ATPase operon gene, was used for the first PCR. The second PCR was carried out by submitting $5 \mu \mathrm{l}$ of $1: 10$ diluted PCR product from the first PCR to an amplification with the following primer pair: MUH-1 5'-TGA CTG GAA GGA TGT TAA GC-3' and MUH-2 $5^{\prime}$-TTTG TAA TCG TCT TTA TTT CG- $3^{\prime} .^{36}$

Amplification reactions were performed in a volume of $50 \mu \mathrm{l}$ containing $10 \times$ PCR buffer with $1.5 \mathrm{mM} \mathrm{MgCl}_{2}$ (Amersham Biosciences, Freiburg, Germany), $0.2 \mathrm{mM}$ each of deoxynucleoside triphosphate (Amersham Biosciences), $1 \mu \mathrm{M}$ of each primer, and $1.25 \mathrm{U}$ Taq DNA polymerase (Amersham Biosciences) and $5 \mu \mathrm{l}$ of DNA template in a Perkin Elmer GeneAmp 2400 thermocycler.

Following an initial denaturation step at $95^{\circ} \mathrm{C}$ for $7 \mathrm{~min}$ utes, the 40 cycle amplification programme consisted of denaturation at $95^{\circ}$ for 20 seconds, annealing at $52^{\circ} \mathrm{C}$ for 2 minutes for the first round and $50^{\circ} \mathrm{C}$ for the second round, and elongation at $72^{\circ} \mathrm{C}$ for 1 minute. The nested PCR generated a $104 \mathrm{bp}$ product which was analysed on a $2 \%$ agarose gel containing ethidium bromide. All positive samples were reconfirmed. The sensitivity of the nested PCR product on gel electrophoresis was 6 ag M pneumoniae FH ATCC 15531 cDNA.

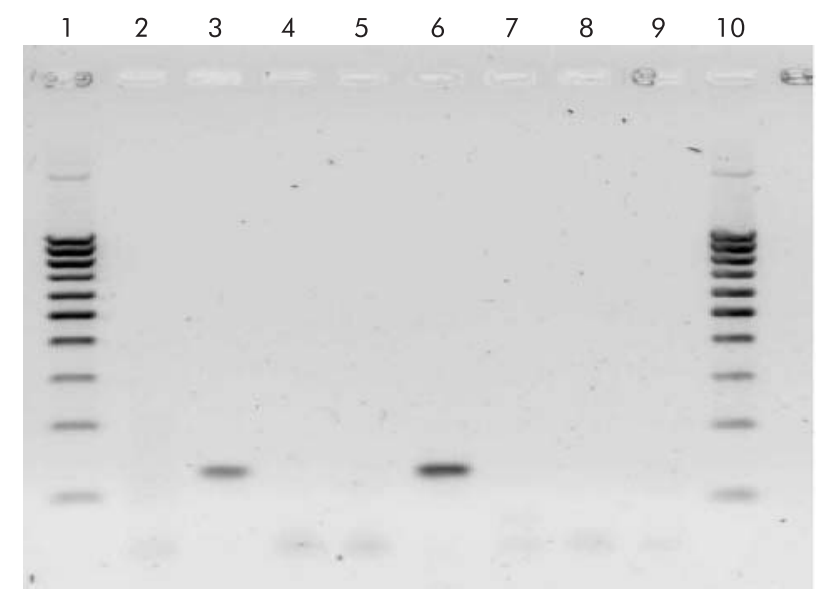

Figure 1 Chlamydophila pneumoniae nested PCR. Lanes 1 and 10, 100 bp DNA ladder; lanes 2-5, clinical samples; lane 6, positive control; lanes 7-9, negative controls. Lanes 3 and 6 show positive $128 \mathrm{bp}$ PCR products for $C$ pneumoniae. 


\section{Chlamydophila pneumoniae}

CP PCR was performed in the same way but using different primers and a different cycling protocol. We used the outer primer pair CpHL-1 5'-GTT GTT CAT GAA GGC CTA CT-3' and CpHR-1 5'-TGC ATA ACC TAC GGT GTG TT-3' which is specific for $\mathrm{CP}^{35}$ and the inner primer pair CpIn-1 $5^{\prime}$-AGT TGA GCA TAT TCG TGA GG-3' and CpIn-2 5'-TTT ATT TCC GTG TCG TCC AG-3'. ${ }^{37}$ These primers amplify a sequence of unknown function of $\mathrm{CP}$ and do not amplify DNA from normal flora or any other respiratory pathogen. ${ }^{38}$

DNA amplification consisted of 32 cycles of $95^{\circ} \mathrm{C}$ for $1: 30 \mathrm{~min}, 55^{\circ} \mathrm{C}$ for $1: 45 \mathrm{~min}$ and $72^{\circ} \mathrm{C}$ for $1: 45 \mathrm{~min}$, after a pre-incubation at $95^{\circ} \mathrm{C}$ for 2 minutes. The resulting products from the first and second PCR had sizes of $438 \mathrm{bp}$ and $128 \mathrm{bp}$, respectively, and were detected by the method described above. The sensitivity of the second product was 48 ag $C$ pneumoniae ATCC VR 2282 cDNA.

\section{Controls}

Each DNA extraction and each PCR was accompanied by three negative (control processed together with patient specimens, PCR master mix control for each round) and a positive control ( $M$ pneumoniae FH ATCC 15531 kindly provided by K Oberle, Freiburg, Germany and $C$ pneumoniae ATCC VR 2282 kindly provided by M Maass, Lübeck, Germany; fig 1).

All samples were tested for the presence of inhibitors by spiking the samples with pACYC 177 (New England Biolabs, Beverly, MA, USA). This vector has a kanamycin cassette which was detected with the primers $\mathrm{Km} 3$ (5'CAATCAGGTGCGACAATC-3') and Km4 (5'-GCAAGATCC TGGTATCGG-3'), amplifying a 586 bp region of this cassette.

Universal contamination precautions were undertaken to ensure that no amplicon contamination of molecular reagents occurred. They consisted of use of barrier filtered pipette tips, extensive surface cleaning with hypochlorite, and physical separation of extraction and reagent preparations and amplificon detection.

\section{Analysis of data}

Statistical analysis was performed with SPSS Version 12.0. Arithmetic means and standard deviation were calculated for continuous data. To calculate statistical significance the Fisher exact test was applied for categorial data and the two sided $t$ test for independent continuous data.

\section{RESULTS}

\section{Patients}

A total of 80 children were enrolled, 26 with asthma, 12 with chronic purulent bronchitis (five with cystic fibrosis, three with primary ciliary dyskinesia, and four with post-infectious bronchiectasis without underlying disease), and 42 control subjects without acute or chronic lung disease. There were no differences in age $(p=0.559$ and $p=0.075$ for the bronchitis and asthma groups, respectively) or sex $(p=0.77)$ between patients and controls (table 1). Asthmatics were more likely to be atopic and to be on regular inhaled steroids than patients with chronic bronchitis $(\mathrm{p}<0.001$ for both items $)$. $\mathrm{FEV}_{1}$ was significantly lower in patients with either asthma or chronic bronchitis than in healthy controls (both $\mathrm{p}<0.001)$.

\section{Sputum induction}

There were no adverse events during or after sputum induction. Induction of adequate amounts of sufficient microscopic quality was possible in $68 \%$ of the patients and $57 \%$ of the controls $(p=0.24)$.

\section{Chlamydophila pneumoniae}

PCR for CP was positive in nine patients $(23.6 \%)$ with chronic lung diseases and in no patient without lung disease $(\mathrm{p}=0.001$, table 2$)$. Subgroups of patients with asthma and with chronic bronchitis were significantly more likely to harbour CP within their airways than controls $(4 / 26 v 0 / 42$; $\mathrm{p}=0.017$ and $5 / 12 \vee 0 / 42 ; \mathrm{p}<0.001$, respectively). The difference between $\mathrm{CP}$ detection rates in children with asthma (15.3\%) and those with chronic purulent bronchitis $(41.6 \%)$ did not reach statistical significance $(p=0.11)$. There was an equal detection rate with nasal swabs and induced sputum (13.2\% $v 19.2 \%)$. Of the five patients with nasal specimens positive for $\mathrm{CP}$, only one (the patient with $\mathrm{CP}$ in both specimens) had concurrent induced sputum of sufficient quality. When only children with successful sputum induction were analysed, five patients (19.2\%) and no controls were positive for CP $(p=0.008)$. Of the five patients with induced sputum specimens positive for $\mathrm{CP}$, four had negative nasal specimens. Three of nine CP positive patients were also positive for MP in the same specimen. The mean (SD) $\mathrm{FEV}_{1}$ was 95.5 (16.7)\% and 90.2 (19.6)\% for positive and negative patients, respectively $(\mathrm{p}=0.45) .40 \%$ of positive and $50 \%$ of negative patients were on regular inhaled steroids $(p=1.0)$. The mean age was 11 years for both CP negative and positive patients $(\mathrm{p}=0.54) .50 \%$ of non-atopic children and $5.6 \%$ of atopic children with asthma were positive for either MP or CP $(p=0.018)$.

\section{Mycoplasma pneumoniae}

$10.5 \%$ of children with chronic lung disease and none of the healthy controls had evidence of infection with MP $(\mathrm{p}=0.044)$. There were no significant differences in detection rates between asthmatics and patients with chronic purulent bronchitis. No patient had a positive result in both nasal and bronchial specimens. Of the four children with MP colonisation, only one had both nasal and successful sputum induction. If only children with successful sputum induction were analysed, no difference was found in colonisation rates with MP (one patient and no control children; $\mathrm{p}=0.42$ ). Three out of four MP positive patients were also positive for

Table 1 Characteristics of patients at study entry

\begin{tabular}{|c|c|c|c|}
\hline & $\begin{array}{l}\text { Asthma } \\
(n=26)\end{array}$ & $\begin{array}{l}\text { Chronic purulent } \\
\text { bronchitis } \\
(n=12)\end{array}$ & $\begin{array}{l}\text { Healthy controls } \\
(n=42)\end{array}$ \\
\hline Mean (range) age (years) & $10.8(7-15)$ & $11.8(7-15)$ & $12.3(6-15)$ \\
\hline Male sex, $\mathrm{n}(\%)$ & $12(46.1 \%)$ & $6(50 \%)$ & $24(57.1 \%)$ \\
\hline Atopy, $\mathrm{n}(\%)$ & $18(69.2 \%)$ & 0 & Not assessed \\
\hline Mean (SD) FEV $1 \%$ predicted) & $94.0(13.9 \%)$ & $86.4(26.7 \%)$ & $109(10.2 \%)$ \\
\hline Bacterial colonisation of sputum & Not assessed & $12(100 \%)^{*}$ & Not assessed \\
\hline $\begin{array}{l}\text { Regular systemic or inhaled antibiotics, } \\
\mathrm{n}(\%)\end{array}$ & 0 & $12(100 \%)$ & 0 \\
\hline Inhaled steroids, n (\%) & $15(57.8 \%)$ & $3(25 \%)$ & 0 \\
\hline
\end{tabular}




\begin{tabular}{|c|c|c|c|c|}
\hline & \multicolumn{2}{|c|}{ Chlamydophila pneumoniae } & \multicolumn{2}{|c|}{ Mycoplasma pneumoniae } \\
\hline & Nasal brush & Induced sputum & Nasal brush & Induced sputum \\
\hline Asthma & $2(7.6 \%)$ & $3(15 \%)$ & $2(7.6 \%)$ & $1(5 \%)$ \\
\hline $\begin{array}{l}\text { Chronic purulent } \\
\text { bronchitis }\end{array}$ & $3(25 \%)$ & $2(33 \%)$ & $1(8.3 \%)$ & \\
\hline Healthy controls & 0 & 0 & 0 & 0 \\
\hline
\end{tabular}

$\mathrm{CP}$ in the same specimen. There was no correlation between a positive test result and $\mathrm{FEV}_{1}$, age, or treatment with inhaled steroids.

\section{DISCUSSION}

To our knowledge, this is the first controlled study in children with stable asthma and stable chronic purulent bronchitis which shows significantly increased rates of airway colonisation with either CP or MP. The design of our study was cross sectional, so we cannot be sure whether this truly reflects persistence of these organisms. As our patients were free of acute exacerbations, however, it seems unlikely that the differences are merely the result of acute infection. Studies in children and adults suggest that most patients with CP positive nasopharyngeal specimens or sputum remain positive over a time period of at least 1 year. ${ }^{24} 39$

Depending on the PCR method used, $1.3-21 \%$ of healthy adults $^{40}$ and $5-6 \%$ of asymptomatic children ${ }^{30}{ }^{41}$ harbour CP DNA in their nasopharaynx or sputum. $44 \%$ of lungs after accidental death of previously healthy individuals stained positive for CP antigens. ${ }^{42}$ Adequate healthy controls must therefore be included in all studies applying direct pathogen detection techniques for CP in clinical specimens.

Only a few PCR studies have been undertaken in patients with stable chronic lung disease, the majority without adequate controls. In patients with COPD the incidence of CP DNA in spontaneous or induced sputum from patients varied from $11.3 \%$ to $59 \% .{ }^{39}{ }^{43}$ In adults with asthma Martin and colleagues found DNA of either CP or MP in 56\% by using a combination of nasal and oropharyngeal swabs, bronchoalveolar lavage fluid, and bronchial brush and biopsy specimens. ${ }^{31}$ In nasopharyngeal swabs CP DNA was detected in $5.4 \%$ of adults with acute asthma and $0.9 \%$ of healthy controls. ${ }^{44}$

Two uncontrolled studies have been performed in children using PCR methods. In a heterogeneous group of children with asthma and recurrent bronchial obstructions, Cunningham et $a l^{24}$ found a rate of $28 \%$ CP DNA but only $3 \%$ MP DNA in nasal specimens of stable asthmatic children and showed that PCR for CP remained positive over several months. Schmidt et $a b^{32}$ reported an incidence of 52\% PCR positivity for $\mathrm{CP}$ in bronchoalveolar lavage specimens in children undergoing broncoscopic investigation for asthma and recurrent bronchial obstruction. Our study corroborates these findings and also shows that these detection rates are significantly increased when compared with healthy controls. Our study further shows that asthmatic children with atopy were less likely to be colonised with either CP or MP than children without atopy. This is in agreement with findings in adults where onset of asthma in adulthood and non-atopic status were correlated with serological evidence of CP infection. $^{12}$

However, the fact that colonisation with either CP or MP occurs in children with asthma or chronic bronchitis, as found in our study, does not establish a causal relationship between infection and inflammation. CP is known to persist within monocytes for a long time without necessarily inducing an inflammatory response. Monocytes and macrophages carry the organism throughout the body ${ }^{45}$ and may settle down in loci of increased inflammatory stimuli. Their increased detection rate in children with chronic lung disease with different immunopathology may just reflect the increased concentration of inflammatory cells within respiratory specimens of inflamed airways.

Biscione and colleagues have recently used a reversed transcriptase PCR to detect RNA of the major outer membrane protein (MOMP) from CP that is only produced during productive infection. Nasal secretions were positive for MOMP-RNA in $6.4 \%$ of adult patients with stable atopic asthma and in only $2.3 \%$ of controls which consisted of the patients' spouses. ${ }^{46}$ This method seems promising for differentiating between colonisation and productive infection.

An intervention trial with antibiotics in patients with repeated PCR measurements of $\mathrm{CP}$ and MP in respiratory specimens will be necessary to clarify whether CP or MP persist in inflamed airways as a pathogenic co-factor or as an innocent bystander. A recent randomised controlled trial of roxithromycin given for 6 weeks to adults with asthma and serological evidence for $\mathrm{CP}$ infection showed a short term increase in evening peak flow but no long term effect. ${ }^{47}$ Another two uncontrolled studies have been performed in patients with positive CP PCR. Blasi et $a^{39}$ demonstrated microbiological success, defined as clearance of CP DNA from blood monocytes, in 59\% of adults with a COPD exacerbation after a 6 week course of azithromycin which was sustained 10 weeks after the treatment in only $29 \%$. In the second uncontrolled study Miyashita et al ${ }^{48}$ reported that clarithromycin given for up to 6 weeks to adult patients with chronic cough eradicated CP from nasal swab specimens and stopped symptoms.

One small controlled study by Kraft et $a l^{49}$ in 55 adults with asthma used direct pathogen detection in bronchoalveolar lavage fluid and bronchial biopsies as the entry criterion. In this study clarithromycin improved $\mathrm{FEV}_{1}$ and decreased concentrations of TNF- $\alpha$, IL-12 and IL-5 compared with placebo only in those asthmatics who were PCR positive for either MP or $\mathrm{CP}$, which suggests that macrolides have a specific antimicrobial effect as well as anti-inflammatory activity. Because of the invasive nature of $\mathrm{CP}$ and MP detection techniques in this study, microbiological success could not be documented by obtaining repeated respiratory specimens during and after the intervention.

Before starting intervention trials PCR detection methods should be replicated in larger numbers of patients and within a longitudinal study. If colonisation with CP or MP can be detected repeatedly in the same patients, combining nasal brush with induced sputum specimens (as in our study) would be a feasible method for measuring microbiological success of antibiotic interventions trials. Performing these trials in children with asthma and other chronic lung diseases would be worthwile as there is evidence from 
animal studies that early treatment may be more effective than later treatment. ${ }^{33}$

\section{ACKNOWLEDGEMENTS}

The authors thank K Oberle, Freiburg, Germany for providing $M$ pneumoniae FH ATCC 15531 and M Maas, Lübeck, Germany for providing C pneumoniae ATCC VR 2282 as positive controls; and Karin Kogelheide, technical assistant at Children's Hospital Bochum, for performing lung function tests and sputum cytopreps as well as supporting sputum induction procedures.

\section{Authors' affiliations}

N Teig, C Schmidt, C Rieger, Children's Hospital of Ruhr University, St Josef Hospital, Bochum, Germany

A Anders, S Gatermann, Institute of Microbiology, Immunology and Hygiene, Ruhr University, Bochum, Germany

The study was supported by a grant from the medical faculty (FoRuM grant) of the Ruhr-University Bochum.

Competing interest: None of the authors has any financial interests in any of the diagnostic tools used in the study.

\section{REFERENCES}

1 Grayston JT. A new respiratory tract pathogen. Chlamydia pneumoniae, strain TWAR. J Infect Dis 1990;161:618-25.

2 Dallo SF, Baseman JB. Intracellular DNA replication and long-term survival of pathogenic mycoplasma. Microb Pathog 2000;29:301-9.

3 Heiskanen-Kosma T, Korppi M, Laurila A, et al. Chlamydia pneumoniae is an important cause of community acquired pneumonia in school-aged children: serological results of a prospective population-based study. Scand J Infect Dis 1999;31:255-9.

4 Volanen I, Vainionpaa R, llonen J, et al. A prospective study of Chlamydia pneumoniae antibodies in children between 7 months and 8 years of age. Scand J Infect Dis 2003:35:471-7.

5 Esposito S, Blasi F, Arosio C, et al. Importance of acute Mycoplasma pneumoniae and Chlamydia pneumoniae infections in children with wheezing. Eur Respir J 2000;16:1142-6.

6 Esposito S, Droghetti R, Bosis S, et al. Cytokine secretion in children with acute Mycoplasma pneumoniae infection and wheeze. Pediatr Pulmonol 2002;34:122-7.

7 Freymuth F, Vabret A, Brouard J, et al. Detection of viral, Chlamydia pneumoniae and Mycoplasma pneumoniae infections in exacerbations of asthma in children. J Clin Virol 1999;13:131-9.

8 Lieberman D, Lieberman D, Ben-Yaakov $M$, et al. Infectious etiologies in acute exacerbations of COPD. Diagn Microbiol Infect Dis 2001;40:95-102.

9 Boman J, Sonderberg S, Forsberg J, et al. High prevalence of Chlamydia pneumoniae DNA in peripheral blood mononuclear cells in patients with cardiovascular disease and in middle-aged blood donors. J Infect Dis 1998;178:274-7.

10 Byrne GI, Quelette SP, Wang Z, et al. Chlamydia pneumoniae expresses genes required for DNA replication but not cytokinesis during persistent infection of Hep-2 cell. Infect Immunol 2001;69:5423-9.

11 Saikku $\mathbf{P}$, Laitinen K, Leionen M. Animal models for Chlamydia pneumoniae infection. Atherosclerosis 1998;140:S17-19.

12 Ten Brinke A, van Dissel JT, Sterk PJ, et al. Persistent airflow limitation in adultonset nonatopic asthma is associated with serologic evidence of Chlamydia pneumoniae infection. J Allergy Clin Immunol 2001;107:449-54.

13 Von HL, Vasankari T, Liippo K, et al. Chlamydia pneumoniae and severity of asthma. Scand J Infect Dis 2002;34:22-7.

14 Von Hertzen L, Toryla M, Gimishanov A, et al. Asthma, atopy and Chlamydia pneumoniae in adults. Clin Exp Allergy 1999;29:522-8.

15 Gencay M, Rüdiger JJ, Tamm M, et al. Increased frequency of Chlamydia pneumoniae antibodies in patients with asthma. Am J Respir Crit Care Med $2001 ; 163: 1097-100$

16 Hahn DL, Anttila T, Saikku P. Association of Chlamydia pneumoniae antibodies with recently symptomatic asthma. Epidemiol Infect 1996:117:513-7.

17 Von Hertzen L, Isoaho R, Leinonen $M$, et al. Chlamydia pneumoniae antibodies in chronic obstructive pulmonary disease. Int J Epidemiol 1996;25:658-64

18 Von Hertzen L, Alakarppa H, Koskinen R, et al. Chlamydia pneumoniae infection in patients with chronic obstructive pulmonary disease. Epidemiol Infect 1997; 118:155-64.

19 Kalayoglu MV, Libby P, Byrne Gl. Chlamydia pneumoniae as an emerging risk factor in cardiovascular disease. JAMA 2002;288:2724-31

20 Villareal C, Whittum-Hudson JA, Hudson AP. Persistent Chlamydia and chronic arthritis. Arthritis Res 2002;4:5-9.
21 Munger KL, Peeling RW, Hernan MA, et al. Infection with Chlamydia pneumoniae and risk of multiple sclerosis. Epidemiology 2003;14:141-7.

22 Emre U, Roblin PM, Gelling M, et al. The association of Chlamydia pneumoniae infection and reactive airway disease in children. Arch Pediatr Adolesc Med 1994;148:727-32

23 Mills GD, Lindeman JA, Fawcett JP, et al. Chlamydia pneumoniae serological status is not associated with asthma in children and young adults. Int J Epidemiol 2000;29:280-4.

24 Cunningham AF, Johnston SL, Julious SA, et al. Chronic Chlamydia pneumoniae infection and asthma exacerbations in children. Eur Respir $J$ 1998; 11:345-9.

25 Dowell SF, Peeling RW, Boman J, et al. Standardizing Chlamydia pneumoniae assays: Recommendations from the Centers for Disease Control and Prevention (USA) and the Laboratory Centre for Disease Control (Canada). Clin Infect Dis 2001;33:492-503.

26 Kern DG, Neill MA, Schachter J. A seroepidemiological study of Chlamydia pneumoniae in Rhode Island. Evidence of serologic cross-reactivity. Chest 1993;104:208-13.

27 Johnston SL. Is Chlamydia pneumoniae important in asthma? Am J Respir Crit Care Med 2001;164:513-4

28 Hammerschlag MR. The intracellular life of chlamydiae. Semin Pediatr Infect Dis 2002;13:239-48.

29 Waring AL, Halse TA, Csiza CK, et al. Development of a genomics-based PCR-assay for detection of Mycoplasma pneumoniae in a large outbreak in New York City. J Clin Microbiol 2001;39:1385-90.

30 Tondella ML, Talkington DF, Holloway BP, et al. Development and evaluation of real-time PCR-based fluorescence assays for detection of Chlamydia pneumoniae. J Clin Microbiol 2002;40:575-83.

31 Martin RJ, Kraft M, Wei $\mathrm{H}$, et al. A link between chronic asthma and chronic infection. J Allergy Clin Immunol 2001;107:595-601.

32 Schmidt SM, Muller CE, Bruns R, et al. Bronchial Chlamydia pneumoniae infection, markers of allergic inflammation and lung function in children. Pediatr Allergy Immunol 2001;12:257-65.

33 Fong IW, Chiu B, Biira E, et al. Can an antibiotic (macrolide) prevent Chlamydia pneumoniae induced atherosclerosis in a rabbit model? Clin Diag Lab Immunol 1999;6:891-4.

34 Kips JC, Fahy JV, Hargreave FE, et al. Methods for sputum induction and analysis of induced sputum: a method for assessing airway inflammation in asthma. Eur Respir J 1998;11(Suppl):9-12s.

35 Bernet C, Garret M, de Barbeyrac B, et al. Detection of Mycoplasma pneumoniae by using the polymerase chain reaction. J Clin Microbiol 1989;27:2492-6.

36 Abele-Horn M, Franck W, Busch U, et al. Transverse myelitis associated with Mycoplasma pneumoniae. Infection 1998;26:909-12.

37 Maass M, Krause E, Engel PM, et al. Endovascular presence of Chlamydia pneumoniae in patients with hemodynamically effective carotid artery stenosis. Angiology 1997;48:699-706.

38 Campbell LA, Perez Melgosa M, Hamilton DJ, et al. Detection of Chlamydia pneumoniae by polymerase chain reaction. J Clin Microbiol 1992:30:434-439.

39 Blasi F, Damato S, Consentini R, et al. Chlamydia pneumoniae and chronic bronchitis: association, severity and bacterial clearance following treatment Chlamydia InterAction with COPD (CIAC) Study Group. Thorax 2002;57:672-6.

40 Miyashita N, Yoshishito N, Nakajima M, et al. Prevalence of asymptomatic infection with Chlamydia pneumoniae in subjectively healthy adults. Chest 2001;119:1416-9.

41 Falck G, Gnarpe J, Gnarpe H. Prevalence of Chlamydia pneumoniae in healthy children and children with respiratory tract infections. Pediatr Infect Dis J 1997; 16:549-54.

42 Wu L, Skinner JM, Lambie N, et al. Immunohistochemical staining for chlamydia pneumoniae is increased in lung tissue from subjects with chronic obstructive pulmonary disease. Am J Respir Crit Care Med 2000; 162:1148-51

43 Smieja M, Leigh R, Petrich A, et al. Smoking, season, and detection of chlamydia pneumoniae DNA in clinically stable COPD patients. BMC Infect Dis 2002;2:12.

44 Miyashita N, Kubota Y, Nakajima M, et al. Chlamydia pneumoniae and exacerbation of asthma in adults. Ann Allergy Asthma Immunol 1998:80:405-9.

45 Moazed TC, Kuo CC, Grayston JT, et al. Evidence of systemic dissemination of Chlamydia pneumoniae via macrophages in the mouse. I Infect Dis 1998;177:1322-5.

46 Biscione GL, Corne J, Chauhan AJ, et al. Increased frequency of detection of Chlamydophila pneumoniae in asthma. Eur Respir J 2004;24:745-9.

47 Black PN, Blasi F, Jenkins CR, et al. Trial of roxithromycin in subjects with asthma and serological evidence of infection with Chlamydia pneumoniae. Am J Respir Crit Care Med 2001;164:536-41.

48 Miyashita N, Fukano H, Yoshida K, et al. Chlamydia pneumoniae infection in adult patients with persistent cough. J Med Microbiol 2003;52:265-9.

49 Kraft M, Casell GH, Pak J, et al. Mycoplasma pneumoniae and Chlamydia pneumoniae in asthma. Effect of clarithromycin. Chest 2002;121:1782-8. 